\title{
HOLOCAUSTO BRASILEIRO: O RESGATE DA MEMÓRIA NO JORNALISMO LITERÁRIO DE DANIELA ARBEX
}

\author{
Leticia Sangaletti \\ Jornalista e Mestra em Letras \\ Doutoranda em Letras pela UFRGS \\ leticiasangaletti@hotmail.com \\ Laísa Veroneze Bisol \\ Jornalista e Mestra em Letras \\ Doutoranda em Letras pela UFSM \\ laisabisol1@gmail.com
}

\section{RESUMO}

O intuito deste artigo é verificar como a memória se constrói na obra de jornalismo literário de Daniela Arbex, "Holocausto Brasileiro", a partir da narrativa textual. A metodologia parte da leitura da obra em consonância com o aporte bibliográfico e segue com uma análise descritiva e comparativa, que mescla as percepções presentes no texto e nas imagens selecionadas. Para tanto, utilizamos como aporte teórico, entre outros autores, Maurice Halbwachs e Paul Ricoeur acerca da Memória. Os resultados da análise do trabalho apontam para o resgate da memória através das formas de narrativa utilizadas na obra, a partir de uma releitura do passado, partindo da individualidade para o coletivo, tanto no resgate, quanto na divulgação dessas memórias.

Palavras-chave: jornalismo literário; memória; fotografia; Holocausto Brasileiro; Daniela Arbex.

\section{ABSTRACT}

The purpose of this article is to verify how the memory is constructed in the work of literary journalism of Daniela Arbex, Brazilian Holocaust, from the textual narrative. The methodology starts from the reading of the work in consonance with the bibliographical contribution and follows with a descriptive and comparative analysis, which merges the perceptions present in the text and in the selected images. For that, we use as a theoretical contribution, among other authors, Maurice Halbwachs and Paul Ricoeur about Memory. The results of the analysis of the work point to the rescue of memory through the forms of narrative used in the work, from a re-reading of the past, starting from the individuality to the collective, both in the rescue and in the dissemination of these memories.

Keywords: Literary journalism; memory; photography; Brazilian Holocaust; Daniela Arbex.

\section{APONTAMENTOS INICIAIS: JORNALISMO LITERÁRIO E MEMÓRIA}


Um dos papéis das manifestações narrativas é o resgate da memória. Um texto ficcional, de não-ficção, imagético, ou a reunião de todos eles é (ou são) capaz(es) de reconstruir os acontecimentos para que não sejam esquecidos e, mais do que isso, quando tratamos de arte ou mídia, compreendemos que essa função vai um pouco além: resguardar memórias significa fazer-saber e, sobretudo, suscitar a reflexão e criticidade diante daquilo que já foi.

Se pensarmos na união da literatura com o jornalismo, temos uma produção que vai além de apresentar reflexos da sociedade, mas que se apresenta como uma forma de reinterpretar o passado e trazê-lo presente para a constituição da memória coletiva. Importa, portanto, a maneira como o faz, para que aquilo que for lido, realmente contribua para a criticidade social. O jornalismo diário, que informa fatos do cotidiano, nem sempre resgata fatores históricos e, muitas vezes, apenas informa situações ligeiras, sem a obrigatoriedade de apresentar um viés reflexivo.

Entretanto, existem formas diversas do fazer jornalístico e, uma delas, é o jornalismo literário, presente em livros-reportagem ou, nomeados de outra forma, romances-reportagem. Esse tipo de romance, que une duas áreas em uma narrativa, é um dos caminhos de resgate e difusão da memória, pois, através de textos e imagens, apresenta diversas temáticas com uma diferença de tempo e espaço com relação aos acontecimentos narrados.

Partindo dessas ideias, este trabalho tem como objetivo verificar como a memória é operada pelo jornalismo, em produções de reportagem investigativas, compreendendo o 
papel do texto nesse processo. Para tanto, selecionamos como corpus do trabalho a obra “Holocausto Brasileiro", escrita pela jornalista mineira Daniela Arbex (2015).

É importante ressaltarmos que sendo o "Holocausto Brasileiro" uma obra que surgiu a partir de uma reportagem investigativa, se faz mister observarmos que, não só a narrativa carregada de elementos literários dá voz e devolve a vida aos personagens sobreviventes do Colônia. Nessa esteira, verificar como se funde o conjunto de elementos que, unidos, dão vida ao jornalismo literário, é pertinente aos estudos de jornalismo e, mais especificamente, de reportagem.

Nosso caminho metodológico parte da leitura da obra, em consonância com o aporte bibliográfico acerca de memória, patrimônio cultural e jornalismo literário e segue com uma análise descritiva e comparativa, que mescla as percepções presentes no texto, dentre as histórias apresentadas pela jornalista.

\section{PATRIMÔNIO CULTURAL E MEMÓRIA ATRAVÉS DAS LINGUAGENS}

Ao falarmos de patrimônio, é comum nos voltarmos aos patrimônios materiais, sem nos darmos conta que existem os imateriais, dentre os quais, estão os associados às nossas memórias, vivências e experiências, sendo elas individuais ou coletivas, como as heranças que recebemos dos familiares, por exemplo. Elas são afetivas e também são culturais, possuem significados e podem cumprir um papel importante no que tange à história de um grupo familiar, por exemplo, ou ainda de uma cidade, país ou da própria sociedade.

Gonçalvez (2003) diz que se construiu uma qualificação de "patrimônio imaterial" ou "inatingível", que visa a aspectos da vida social e cultural, e que recai mais nos aspectos ideais e valorativos de formas de vida, dificilmente abrangidos por concepções mais 
tradicionais. Conforme o autor, "nessa nova categoria estão lugares, festas, religiões, formas de medicina popular, dança, culinária, técnicas etc" (2003, p. 28).

O que é citado por Gonçalvez (2003) como patrimônio imaterial está intimamente ligado à cultura de um povo, de uma sociedade, de um lugar, sendo resultado de ações que ultrapassaram o tempo, foram mantidas e que além da memória, toraram-se também, patrimônio cultural. No Brasil, a Constituição Federal (1988) estabelece, no artigo 216:

Art. 216. Constituem patrimônio cultural brasileiro os bens de natureza material e imaterial, tomados individualmente ou em conjunto, portadores de referência à identidade, à ação, à memória dos diferentes grupos formadores da sociedade brasileira, nos quais se incluem:

I - as formas de expressão;

II - os modos de criar, fazer e viver;

III - as criações científicas, artísticas e tecnológicas;

IV - as obras, objetos, documentos, edificações e demais espaços destinados às manifestações artístico-culturais;

V - os conjuntos urbanos e sítios de valor histórico, paisagístico, artístico, arqueológico, paleontológico, ecológico e científico.

§10 O poder público, com a colaboração da comunidade, promoverá e protegerá o patrimônio cultural brasileiro, por meio de inventários, registros, vigilância, tombamento e desapropriação, e de outras formas de acautelamento e preservação.

§ 2ㅇ Cabem à administração pública, na forma da lei, a gestão da documentação governamental e as providências para franquear sua consulta a quantos dela necessitem.

§ 3ㅇ A lei estabelecerá incentivos para a produção e o conhecimento de bens e valores culturais.

§ 4 Os danos e ameaças ao patrimônio cultural serão punidos, na forma da lei. 
§ 5 ㅇ Ficam tombados todos os documentos e os sítios detentores de reminiscências históricas dos antigos quilombos (BRASIL, 1988).

Sendo as obras de jornalismo literário como produções não-ficcionais, podemos pensar que tais memórias são como as heranças recebidas dos familiares, por exemplo, afetivas e também culturais, que possuem significados e podem cumprir um papel importante no que tange à história de um grupo familiar ou ainda de uma cidade, país ou da própria sociedade.

Ao compreendermos o modo como o patrimônio cultural imbrica-se com a memória, adentramos na perspectiva de Dominique Wolton (2004). O autor explica que a comunicação tem a função de fazer o passado se perpetuar com vistas ao futuro, uma vez que os processos comunicacionais também auxiliam na construção da memória. Diante disso, apresentamos alguns conceitos que dizem respeito a esse fenômeno.

Walter Benjamin (1994, p. 224) afirma que "articular historicamente o passado não significa conhecê-lo 'tal como ele de fato foi'. Significa apropriar-se de uma reminiscência, tal como ela relampeja no momento de perigo". Essa afirmativa confirma a ideia de que, mesmo o fazer jornalístico, que não é ficcional, não pode remontar os fatos exatamente do modo como aconteceram, já que a linguagem perpassa por um canal de interpretações antes de ser divulgada. O mesmo vale quando tratamos de fotografia, uma vez que há elementos que não são captados pela câmera, enquanto outros são escolhidos para compor as cenas representadas. Sendo assim, a memória transmitida a partir dessas diferentes formas de linguagem trata-se de uma releitura do passado, a partir das considerações do presente, ainda que esse passado não esteja em um patamar longínquo. 
Ademais, para além da produção do conteúdo memorial, existe a memória que é oriunda das obras, ou seja, formada a partir da leitura de textos ou imagens que tornam o saber possível. Conforme Maurice Halbwachs (2006), a memória é constituída a partir das nossas lembranças unidas à percepção do presente. $\mathrm{O}$ autor destaca que há duas formas de organização das lembranças: uma delas, centrada no próprio indivíduo com suas percepções, que seria a memória individual; e outra, inserida em uma sociedade, com ideias compartilhadas, configurando-se na memória coletiva. Nesse sentido, e ainda segundo o estudioso, "nossa impressão pode se basear não apenas na nossa lembrança, mas também na de outros" (HALBWACHS, 2006, p. 29). Partindo dessa premissa, compreendemos que a memória não se forma apenas acerca das lembranças e percepções individuais, mas a partir da união de diversas vozes que fazem parte da constituição de sentido, ou seja, uma obra que resgata acontecimentos históricos pode vir a fazer parte do imaginário social e, a partir disso, proporcionar novos modos de interpretação acerca do mundo.

As experiências históricas vivenciadas pelos brasileiros podem ser simplesmente relembradas ou podem provocar algum tipo de inquietação, na busca por transformar uma dada realidade. Ao citar Richard, Ginzburg (2012, p. 221) afirma: “O passado é constantemente reinterpretado, em um trabalho sempre incompleto. A memória coletiva não é 'depósito fixo de significações inativas', consenso estabelecido à força, mas resultado de constantes reescritas de "hipóteses e conjecturas'".

O jornalismo apresenta-se como uma forma de reinterpretar o passado e trazê-lo presente para a constituição da memória coletiva. Importa, portanto, a maneira como o faz, para que aquilo que for lido, realmente contribua para a criticidade social. O jornalismo 
diário, que informa fatos do cotidiano, nem sempre resgata fatores históricos e, muitas vezes, apenas informa situações ligeiras, sem a obrigatoriedade de apresentar um viés reflexivo.

Entretanto, existem formas diversas do fazer jornalístico e, uma delas, é o jornalismo literário, presente em livros-reportagem ou, nomeados de outra forma, romances-reportagem. Esse tipo de romance, que une duas áreas em uma narrativa, é um dos caminhos de resgate e difusão da memória, pois apresenta diversas temáticas com uma diferença de tempo e espaço com relação aos acontecimentos narrados.

De acordo com Felipe Pena (2006), o jornalismo encontra na literatura formas de tornar o texto mais atraente, ou seja, a narrativa vai além das técnicas utilizadas na construção de notícias, para aprofundar ideias e contextos a partir de uma linguagem diferenciada, com maior riqueza de detalhes, o que assemelha a leitura não-ficcional com aquela equivalente à ficção.

No jornalismo literário, a realidade é representada de uma forma mais ampla, ou seja, ao passo que as notícias diárias informam com imediatismo os fatos como eles são, o jornalismo com o acréscimo da linguagem literária abrange outros aspectos: históricos, contextuais, culturais, com entrevistas mais extensas e pontos de vista diversos. Referência no assunto, Tom Wolfe explica os caminhos do surgimento dessa linguagem, a partir dos romances-reportagem:

No começo dos anos 60, uma curiosa ideia nova, quente o bastante para inflamar o ego, começou a se insinuar nos estreitos limites da statusfera das reportagens especiais. Tinha um ar de descoberta. Essa descoberta, de início modesta, na verdade, reverencial, poderíamos dizer, era que talvez fosse possível escrever 
jornalismo para ser... lido como um romance. Como um romance, se é que me entendem. Era a mais sincera forma de homenagem ao Romance e àqueles grandes, os romancistas, claro (WOLFE, 2005, p. 19).

Assim, os jornalistas pegam como empréstimo o fazer literário para qualificar os textos, o que é um ganho para a sociedade, que pode ter acesso a informações novas, aprofundadas, bem mais apuradas e estruturadas a partir de uma percepção que não se tinha quando os fatos aconteceram. Além da linguagem escrita, essa ferramenta utiliza-se de outro elemento importante para constituir-se - a fotografia, utilizada também nos noticiários diários, mas com uma nova roupagem quando passa a fazer parte dessas obras.

\section{HOLOCAUSTO BRASILEIRO: A MEMÓRIA NO JORNALISMO LITERÁRIO DE DANIELA ARBEX}

Daniela Arbex é jornalista no Jornal Tribuna de Minas, em Juiz de Fora, e foi para esse empreendimento jornalístico que ela escreveu uma sequência de reportagens sobre o Colônia, maior hospício do Brasil, localizado na cidade de Barbacena, no estado de Minas Gerais. A gama de reportagens originou a obra "Holocausto Brasileiro", publicada em 2013.

A profissional do jornalismo impresso, como diz Eliane Brum no prefácio do livro, "luta contra o esquecimento. Transforma em palavra o que era silêncio. Faz memória. Nesse livro, Daniela Arbex devolve nome, história e identidade àqueles que, até então, eram registrados como 'Ignorados de tal'” (ARBEX, 2015, s/p.).

Arbex (2015) tem o cuidado de resgatar a memória dos sobreviventes desse holocausto, não só dos pacientes, mas de funcionários do local, e procura as personagens das fotos feitas pelo fotógrafo Luís Alfredo, na década de 60, de modo a Ihes dar dignidade. Assim foi com a Sônia, que ficou internada por mais de 40 anos no Colônia, e era 
considerada tutora do grupo e temida por muitos, já que, por um lado, adotou comportamento agressivo, mas, por outro, ajudava as pessoas.

Terezinha, outra esquecida, conhecia o melhor lado da amiga. Sônia improvisava socorro nas crises de otite de Terezinha, quando não havia sequer analgésico para amenizar a dor. Aquecia remendos de cobertor no pátio, sustentava a cabeça da protegida entre os braços e aproximava o pano do ouvido que latejava sem trégua. Sentada no chão de cimento, ela repetia o gesto até que a amiga adormecesse em seu colo. Mantinha o cuidado pelos dias seguintes na tentativa de fazer a inflamação ceder. Nunca mais se separaram. Quase cinco décadas depois, permanecem juntas, como se uma tivesse saído de dentro da outra (ARBEX, 2015, s/p).

A expressão "outra esquecida", já dá indícios do resgate realizado pela autora: dentre tantas pessoas esquecidas, silenciadas ou até mesmo anuladas ao longo da história do Colônia, algumas dessas puderam se tornar conhecidas, através das suas dores, com a representação nessa obra de jornalismo literário. Essas ideias vão ao encontro das perspectivas de Ginzburg (2012 p. 220), de acordo com o pesquisador, os discursos, transpostos de forma ficcional ou não-ficcional, formam a composição de uma memória social, o autor questiona: "O que deve ser lembrado, o que deve ser lido?". As experiências históricas vivenciadas pelos brasileiros podem ser simplesmente relembradas ou podem provocar algum tipo de inquietação, na busca por transformar uma dada realidade. A partir do questionamento do pesquisador, podemos supor que essas são histórias a serem lembradas, uma vez que pouco se conhecia acerca do horror enfrentado pelos indivíduos obrigados a abdicar de suas vidas.

Ao apresentar questões como a necessidade de socorro, a doença, o frio, a escassez de estrutura básica para sentar-se, por exemplo, e o tempo de vivência de todos esses fatores, a narrativa instiga o leitor a resguardar aquilo que de fato se passava em Barbacena, 
detalhes não revelados à época em que ocorriam. Ademais, ao resgatar esses acontecimentos, é possível que se tenha conhecimento desses episódios violentos, ao mesmo tempo em que se reconhece a necessidade de revisitar o que perpassa pela história política, econômica e social do país.

A personagem Sônia teve um final feliz: foi levada junto à amiga Terezinha para a comunidade terapêutica, para viver com dignidade. O texto que conta sua história traz memórias entristecedoras, que se fundem com as de tantos outros internos que viveram no hospício de Barbacena. Nem mesmo a data de nascimento de Sônia era precisa, sendo Barbacena a cidade mencionada nos documentos, ainda que a personagem não fosse oriunda de lá. De acordo com o relato de Arbex (2015, s/p),

Sônia cresceu sozinha no hospital. Foi vítima de todos os tipos de violação. Sofreu agressão física, tomava choques diários, ficou trancada em cela úmida sem um único cobertor para se aquecer e tomou as famosas injeções de "entorta", que causavam impregnação no organismo e faziam a boca encher de cuspe. Deixada sem água, muitas vezes, ela bebia a própria urina para matar a sede. Tomava banho de mergulho na banheira com fezes, uma espécie de castigo imposto a pessoas que, como Sônia, não se enquadravam às regras (ARBEX, 2015, s/p).

O texto ainda apresenta o relato que a interna, assim como outros, passava pelo processo de lobotomia, uma intervenção cirúrgica no cérebro, considerada uma técnica atroz, tendo em vista a gravidade do procedimento. Outras memórias de Sônia são descritas no texto: marcas de maus-tratos, infecções, desenvolvimento de agressividade e, inclusive, ações quase inimagináveis para um ser humano, como podemos observar em: "Num dia de fúria e dor, arrancou o próprio dente com um alicate, porque não aguentava mais sentir o 
rosto latejar. Respondeu com violência ao período mais cinza da sua vida. Passou a ser temida, aprendeu a odiar" (ARBEX, 2015, s/p).

Através de relatos como da personagem Sônia, é possível compreender como os demais internos do Colônia sobreviviam. Exposição física e psicológica à violência e condições sub-humanas de sobrevivência demarcam o espaço descrito na obra. Diante dessas formas de representação, remetemos aos estudos de Paul Ricoeur (2007), já que o teórico enfatiza que cada memória individual trata de um ponto de vista acerca da memória coletiva. No que concerne às reflexões relacionadas às memórias individual e coletiva, três traços que podem ser notados em favor do caráter fundamentalmente privado da memória são propostos por Ricoeur (2007): a memória radicalmente singular, a memória que reside no passado e a passagem de tempo que está vinculada à memória. Sobre eles, o teórico postula:

Primeiro, a memória parece de fato ser radicalmente singular: minhas lembranças não são as suas. Não se pode transferir as lembranças de um para a memória do outro. Enquanto minha, a memória é um modelo de minhadade, de possessão privada, para todas as experiências vivenciadas pelo sujeito. Em seguida, o vínculo original da consciência com o passado parece residir na memória. Foi dito com Aristóteles, diz-se de novo mais enfaticamente com Santo Agostinho, a memória é passado e esse passado é o de minhas impressões; nesse sentido, esse passado é meu passado. É por esse traço que a memória garante a continuidade temporal da pessoa e, por esse viés, essa identidade cujas dificuldades e armadilhas enfrentamos acima. Essa continuidade permite-nos remontar sem ruptura do presente vivido até os acontecimentos mais longínquos de minha infância (RICOEUR, 2007, p. 107-108).

Ricouer (2007) é perspicaz, ao demonstrar no que tange à individualidade e à coletividade das memórias, uma vez que, mesmo com todas as diferenças, as memórias precisam de uma ponte de ligação. Essa ideia permite observar o predomínio da memória 
individual sobre a coletiva, mesmo considerando que as individuais estão arraigadas, enraizadas nas coletivas.

Dessa forma, ainda que o ponto de partida seja a contextualização do hospício através de personagens específicas e suas histórias, através delas se restitui a vivência de uma coletividade. Para além disso, ao passo em que se projetam, através de uma obra como "Holocausto Brasileiro", pontos de vista acerca de um determinado contexto, essas impressões também podem ser apropriadas pelos leitores, sendo possível a reconstrução de um episódio sórdido na história do país.

Outra personagem do Colônia que tem a história resgatada na obra é Maria Cibele Aquino, que foi internada aos catorze anos no Colônia e ilustra o quinto capítulo da obra, intitulado "Os meninos de Oliveira". Ela aparece em uma fotografia no pátio do hospício, está sentada no chão, olhando para cima, de boca aberta e parece desnorteada. A situação deplorável vivida por ela, que faleceu em 2011, dentro do hospital, pode ser encontrada em outra imagem, em que ela, já bem mais velha, está sentada no chão, beijando o rosto de uma boneca. A representação dessa personagem é explorada na obra também em forma de narrativa textual:

Despediu-se da vida na companhia das bonecas que ninou durante toda uma vida de aprisionamento. Chegou ao hospício aos catorze anos e nunca saiu de lá. Elzinha teve mais sorte do que Cibele. Recebeu alta em 2004, após trinta e sete anos de institucionalização, quando foi levada para uma residência terapêutica em Barbacena. Com cinquenta e sete anos, foi a primeira vez que morou em uma casa de verdade (ARBEX, 2015, $s / p)$.

Podemos observar a literalidade presente no texto de cunho jornalístico, isso porque, ao ler esse excerto, já é possível imaginar a imagem que também se ilustra pela fotografia 
apresentada, ou seja, a articulação detalhada do texto, nos permite ir para além da simples informação, para chegar a um patamar próximo ao de reconstituir a ideia do que poderia ter sido o sofrimento das pessoas mencionadas. Ao focar na proximidade com a boneca, seja pela fotografia ou pelo texto, a obra resgata os sentimentos de Maria Cibele, que muito possivelmente buscava seu consolo em memórias da infância que, representadas pelo brinquedo, remetem à constituição de uma outra memória, a da dor.

Além disso, há uma articulação muito fecunda entre as histórias, já que uma outra personagem é lembrada em um mesmo fragmento, sob a justificativa de ter tido mais sorte, uma vez que pôde experienciar a vida fora de Colônia. Ao referir-se a esse acontecimento como "sorte", a autora propicia que pensemos nos direitos básicos do ser humano, uma vez que o leitor se depara com a história de uma vida aprisionada que, quase adentrando a terceira idade, têm pela primeira vez a oportunidade de estar em uma moradia comum.

Pierre Nora (1993) afirma que a história e a memória estão imbricadas, ou seja, a partir dos fatos históricos, se chega à construção da memória coletiva. O estudioso acredita que, embora conceitualmente história e memória sejam diferentes, elas se entrelaçam à medida que a história se encarrega de executar uma função na memória social, resgatando acontecimentos e, portanto, contribuindo para a constituição dessas lembranças: “a história tornou-se uma ciência social e a memória um fenômeno puramente privado. A nação-memória terá sido a última encarnação da história-memória" (NORA, 1993, p. 12). Sob esse aspecto, podemos nos questionar em que medida as narrativas jornalísticas, enquanto pertencentes das ciências sociais, e as obras de ficção, que muitas vezes remetem à história, podem atuar com os dois papeis: tanto no sentido da conservação histórica dos 
fatos como no imaginário social, através da constituição da memória dos seus integrantes. Ao unir os dois tipos de narrativa, como faz Arbex (2015), informando fatos históricos através de uma linguagem que é jornalística e literária, personagens reais como Sônia, Cibele e Elzinha, acabam representando a realidade de tantas outras, para constituir um enredo que auxilia na consolidação dessa história-memória.

Nessa esteira de análise, outra situação que choca o leitor é o fato de Sílvio Savat, interno do Colônia, ter sido confundido com um cadáver, pois tinha o corpo coberto de moscas. Diferente de Cibele e aproximando-se da história de Elzinha, o ex-menino de Barbacena conseguiu sobreviver ao holocausto e foi viver no Cepal, em Belo Horizonte.

O episódio mencionado acima é representado em fotografia e também textualmente justamente a partir da descrição da forma como se originou imagem: "Na ocasião, o corpo dele estava coberto de moscas, dando ao autor da foto a impressão de estar vendo um cadáver" (ARBEX, 2015, s/p). A memória resgatada nesse ponto se funde entre texto e imagem, já que uma é praticamente a descrição da outra, tendo em vista que a fotografia pôde transmitir ao leitor diferentes sentimentos, dentre eles, piedade, dor e indignação. A informação é complementada com o seguinte excerto:

Quando eles chegaram a Belo Horizonte, em 1980, não pareciam meninos, mas bichos assustados. Estavam sujos, não sabiam comer, nem ao menos usar o banheiro. Passaram a infância sem receber estímulos, e, por isso, o quadro de deficiência agravou-se. Silvio, por exemplo, o menino confundido com um cadáver em 1979, mal conseguia se sentar. Rastejava em boa parte do tempo. - O Silvio, como os outros, chegou aqui imundo. Vieram para passar um dia e acabaram ficando a vida inteira. Quem os recebeu ficou chocado com o estado dos vinte e tantos meninos de Barbacena. Fizemos todo um trabalho de resgate da cidadania. Nenhum dos quatro vivos fala, 
mas a gente entende o que eles querem, inclusive seus gritos. $\mathrm{O}$ bonito de verdade é que eles não têm mais o olhar perdido (ARBEX, 2015, s/p).

Mais uma vez os exemplos individuais asseguram a situação da coletividade. Como o excerto apresenta, as crianças eram inúmeras, mas a história de todos se individualiza a partir da representação de Silvio. Assim como em grande parte da obra, esse trecho que citamos remete aos horrores vivenciados naquele lugar. Conforme Maurice Halbwachs (2006), a memória é constituída a partir das nossas lembranças unidas à percepção do presente. Da investigação realizada, unida às suas percepções, a autora de "Holocausto Brasileiro" consegue resgatar a história e transpor essas memórias de sofrimento para a coletividade conhecer e questionar o sistema vivenciado em Colônia. A riqueza de detalhes com que narra as atrocidades que enfrentavam, torna o texto ainda mais propício à reflexão.

Maurice Halbwachs (2006) afirma que a partir das lembranças existem memórias individuais e coletivas. A primeira vale-se da segunda para admitir lembranças ou preencher lacunas. As duas podem também ser consideradas como memória pessoal e social, ou memória autobiográfica e memória social. A primeira sempre recebe ajuda da segunda, tendo em vista que a história da vida individual faz parte da história em geral. Em suas palavras,

é na memória histórica que temos de nos basear [...] As lembranças coletivas vieram se aplicar sobre as lembranças individuais e assim poderíamos agarrá-las mais cômoda e mais seguramente; mas para isso será preciso que as lembranças individuais já estejam ali, senão nossa memória funciona no vazio (HALBWACHS, 2006, p. 80).

É conveniente pensarmos que a obra de jornalismo literário analisada nesta pesquisa segue a perspectiva de Halbwachs (2006), uma vez que, partindo de uma memória histórica 
sobre o Colônia, Arbex (2015) buscou histórias individuais que, com segurança, nas coletivas vieram à tona.

\section{APONTAMENTOS FINAIS}

A função social do jornalismo é indiscutível, assim como a sua importância para a perpetuação da memória, enquanto documento comprobatório de fatos e situações que ocorreram durante determinados períodos e que marcaram a história da vida de pessoas, de cidades, estados e de uma nação.

Assim é o caso da história do Hospital Colônia, um dos maiores hospícios do Brasil, que teve sua história e memória revividas por meio da prática de reportagem e do jornalismo, e o trabalho investigativo da jornalista Daniela Arbex contribui muito para que não caísse no esquecimento.

Tomando como base as ideias de Walter Benjamin (1994), que citamos anteriormente, no que concerne às releituras do passado transpostas para a narrativa, concluímos que mesmo o fazer jornalístico, que não é ficcional, não pode remontar os fatos exatamente do modo como aconteceram, já que a linguagem perpassa por um canal de interpretações antes de ser divulgada. O mesmo vale quando tratamos de fotografia, uma vez que há elementos que não são captados pela câmera, enquanto outros são escolhidos para compor as cenas representadas. Sendo assim, a memória transmitida a partir dessas diferentes formas de linguagem que aparecem na obra "Holocausto Brasileiro", trata-se de uma releitura do passado, a partir das considerações do presente, ainda que esse passado não esteja em um patamar longínquo. 
A fusão do jornalismo com a literatura em um texto que não apenas informa, mas atribui detalhes e sentimentos aos casos expostos, unido ainda à fotografia, que imageticamente recria as situações e oportuniza voz aos envolvidos, forma uma obra completa que resgata de maneira ímpar a memória de anos de sofrimento silenciados por todo o país. Dentre tantas personagens mencionadas pela jornalista Daniela Arbex, selecionamos apenas algumas que representam uma coletividade marcada por sofrimento.

\section{REFERÊNCIAS}

ARBEX, Daniela. Holocausto Brasileiro. São Paulo: Geração, 2015. Edição Kindle.

BENJAMIN, Walter. Sobre o conceito de história. In: BENJAMIN, Walter. Magia e técnica, arte e política: ensaios sobre literatura e história da cultura. Tradução Sérgio Paulo Rouanet. São Paulo: Brasiliense, 1994. p. 222-232.

BRASIL. Constituição Federal de 1988. Promulgada em 5 de outubro de 1988. Disponível em <http://www.planalto.gov.br/ccivil_03/constituicao/constituição.htm>.

GINZBURG, Jaime. Crítica em tempos de violência. São Paulo: Editora da Universidade de São Paulo/Fapesp, 2012.

GONÇALVEZ, José R. O patrimônio como categoria de pensamento. In: ABREU, Regina; CHAGAS, Mario (Orgs.). Memória e patrimônio: ensaios contemporâneos. Rio de Janeiro, DP\&A, 2003. p. 25-33.

HALBWACHS, Maurice. A memória coletiva. Tradução Beatriz Sidou. São Paulo: Centauro, 2006.

KOSSOY, Boris. Os tempos da fotografia: o efêmero e o perpétuo. Cotia, SP: Ateliê, 2007. Fotografia \& história. 2 ed. São Paulo: Ateliê Editorial, 2001.

LIMA, Edvaldo Pereira. Jornalismo e literatura: aproximações, recuos e fusões. In: Anuário Unesco/Metodista de Comunicação. Anuário Unesco/Metodista de Comunicação Regional, Ano 13 n.13, jan/dez. 2009. p. 145-159.

NORA, Pierre. Entre memória e história. Trad. Yara AunKhoury. Projeto História, São Paulo, n. 10, p. 7-28, dez. 1993. Disponível em:

<http://www.pucsp.br/projetohistoria/downloads/revista/PHistoria12.pdf>. Acesso em: 20 jan. 2018. 
PENA, Felipe. Jornalismo literário. São Paulo: Contexto, 2006.

PEREIRA, Rosa Claudia Cerqueira. Literatura \& fotografia: algumas reflexões sobre a cidade de Belém no início do século XX. Anpuh - XXIII Simpósio Nacional de História - Londrina, 2005. em: <http://anais.anpuh.org/wp-content/uploads/mp/pdf/ANPUH.S23.1524.pdf>. Acesso em: 12 jan. 2018.

RICOUER, Paul. A memória, a história e o esquecimento. Campinas, SP: Unicamp, 2007.

SONTAG, Susan. Diante da dor dos outros. São Paulo: Companhia das Letras, 2003.

WOLFE, Tom. Radical chique e o novo jornalismo. São Paulo: Companhia das Letras, 2005.

Artigo recebido em: 04 de maio de 2018.

Artigo aprovado em: 20 de junho de 2018. 